\title{
FIGURAS PARTICIPATIVAS DE LOS TRABAJADORES EN LA PREVENCIÓN DE RIESGOS EN LAS OBRAS
}

\author{
(WORKERS AS PARTICIPATING FIGURES IN THE RISK PREVENTION IN WORKS)
}

Gerardo de Gracia Pastor y Rafael Díaz, Expertos en Seguridad

FECOMA-Comisiones Obreras

Fecha de recepción: 14-I-93

\section{RESUMEN}

Al hilo de la creación de la Fundación Laboral, prevista en el Convenio General a las puertas de la Ley de Prevención de Riesgos Profesionales, en el contexto europeo se plasma esta exposición sociológica en la cual se alerta sobre algo que, para los que se dedican a prevenir, es obvio que están abocados al fracaso si los productores no participan.

\section{SUMMARY}

Along with the creation of the Labour Foundation projected in the General Agreement and the imminence of the Law of Professional Risk Prevention, this sociological report is drawn up in a European context. It serves to alert us on something that is obvious to those in the business of prevention, namely, if producers do not participate we are doomed to failure.
La aportación que desde Comisiones Obreras se hace a la Seguridad en la Construcción no es desde la óptica de la denuncia (nada más fácil) de situaciones de riesgo estructural, permanente y extremo que, desgraciadamente, con tanta frecuencia se da en las obras. Nos preocupa el accidente mortal que cada día, lamentablemente, está ocurriendo en algún punto de España. O los 3.000 accidentes graves que ocurren cada año. O los 140.000 accidentes catalogados como leves que cada uno de los últimos años registran las estadísticas oficiales. Y nos preocupa, con ser grave y extrema la situación actual, no ser capaces (entre todos los agentes implicados en el proceso constructivo) de atajar la tendencia persistente a los muchos y constantes accidentes en las obras. En definitiva, nos preocupa esta situación porque miramos al futuro, porque queremos contribuir a cortar esta tendencia de riesgo extrema. Desde nuestra óptica sindical queremos contribuir a la prevención en construcción.
Lo primero que queremos poner de manifiesto es el aspecto de participación de los trabajadores y sus representantes en el área de prevención. Aspecto que muchas veces ha servido como motivo para otras reivindicaciones o se ha usado como arma arrojadiza.

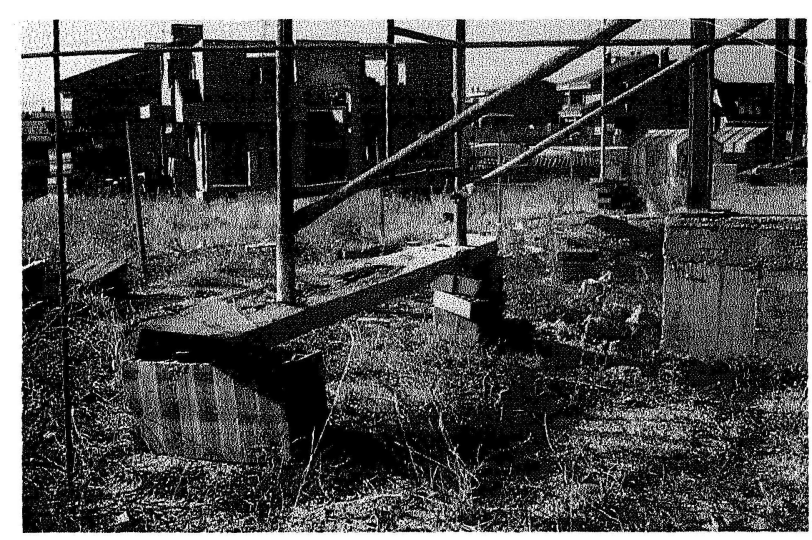

Andamio apoyado en cualquier cosa que se encuentra a mano. 


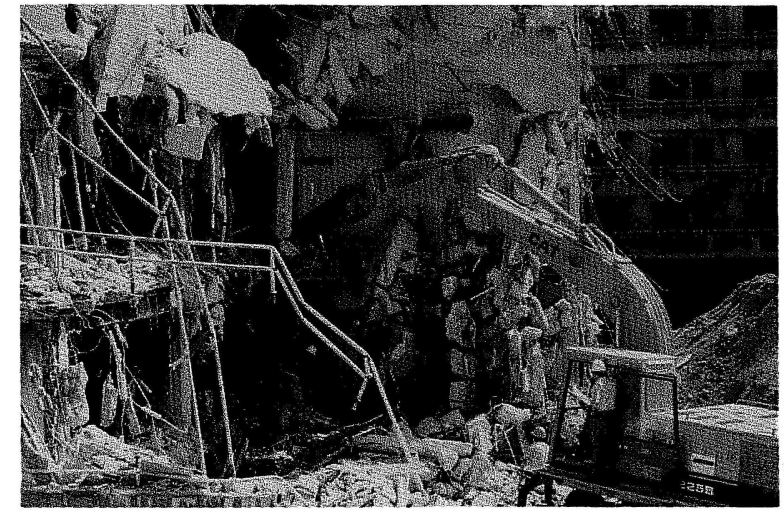

Todos los hombres son cómplices del previsible accidente.

Estamos en otro momento. Las Centrales Sindicales venimos dando muestras de responsabilidad en el área de prevención desde tiempo atrás. Asimismo venimos desarrollando una contribución positiva. Se trata de continuar dicha contribución, de participar en positivo con los puntos que a continuación enumeramos:

\section{DELEGADO DE PREVENCIÓN}

Figura contemplada en el Anteproyecto de Ley de Riesgos Profesionales y Salud Laboral, Artículos 31-32-3334-35 específicos. Así como la Recomendación del Convenio de la OIT sobre construcción del año 1988, Artículo 6.b. Esta figura es totalmente necesaria como expresión participativa de los trabajadores en cada obra.

El propio R.D. 555/86 obliga a entregar una copia del Plan de Seguridad (adaptado por el constructor al estudio diseñado por el profesional respectivo) al vigilante de seguridad, vocal del Comité de Seguridad o al Representante de los trabajadores.

De mala manera se cumplirá este requisito, aun existiendo voluntad (que no siempre existe) y aún reduciendo la exigencia de seis a tres meses de antigüedad para ser representante - por Convenio General-, cuando lo habitual en la construcción son los contratos temporales y éstos reducidos. De ahí la exigencia de nombrar al delegado de prevención al comienzo de la obra. Por ello, debemos actuar todos usando las fórmulas existentes.

El Técnico de Prevención necesita un interlocutor desde el lado de los trabajadores, receptivo a sus estudios diseñados y planes a plicar.
La constructora tiene que dejar de ver al Delegado y Representante de los trabajadores como una figura que no le queda más remedio que tolerar y admitir.

Los trabajadores van a asumir un compromiso y un reto que no siempre entienden y que, muchas veces, interpretan con bastante lógica para cargar responsabilidades que corresponden a otros en la obra.

No cabe duda de que las Centrales Sindicales asumimos un reto importante. No nos va a resultar fácil captar candidatos para esta labor. Hay que formarles, continuamente asesorarles y siempre estar pendiente de sus actuaciones. Es la mejor inversión a medio plazo, ya que el trabajador que asume esta tarea de prevención se está haciendo un especialista, y como tal a las constructoras les interesaría que estos trabajadores continuasen con esa misma labor en futuras obras.

Esto es algo que las grandes constructoras españolas conocen bien y lo vienen llevando a cabo a través de los equipos de seguridad dedicados a tapar huecos, poner barandillas, colocar redes, etc.

\section{COMISIÓN PROVINCIAL DE SEGURIDAD}

Tanto a nivel institucional, presidida por el Director Provincial de Trabajo, como a nivel de Convenio Provincial, también existe esta figura de la Comisión. Las funciones lógicas de esta Comisión pueden concretarse en:

- Información de los estudios visados y planes aprobados, así como estadísticas de accidentes leves, graves y mortales.

- Creación de un Registro de Datos, Archivo y Documentación.

- Organizar un calendario de actuaciones selectivas según gravedad de riesgos, trabajadores expuestos y envergadura-complejidad de la obra.

- Llevar a efecto un calendario de constitución de delegados de Prevención y Comités de Seguridad.

- Montar un calendario de formación específica a representantes, Mandos Intermedios, Jefes de Obra y Profesionales-Técnicos. 
- Desarrollar investigaciones concretas ante actuaciones específicas.

- Verificar el cumplimiento estricto de toda la Normativa vigente, tanto española como comunitaria, con criterios prevencionistas y no reglamentaristas.

Lógicamente, debe existir una programación plurinacional de actividades de promoción de la prevención con análisis de cumplimiento y resultados obtenidos. Todo ello desde la perspectiva del cambio de actitudes ante la prevención y ante la aplicación de la Normativa por parte de todos los agentes implicados en el proceso constructivo: Promotor, Administración, Constructor, Profesional-Técnico, Mando Intermedio, Representante de los trabajadores y Trabajador.

\section{ESTRUCTURA ESTATAL PREVENTIVA}

La estructura preventiva a crear tendrá posibilidad de concretarse en el Marco del Organismo-Función Laboral, recientemente firmado en el Convenio General de Construcción entre las Federaciones FECOMA-CC.OO., FEMCA-UGT y la Patronal del sector CNC.

Su misión principal debe partir de los supuestos aceptados por todos y evidentes por sí mismos:

- Contribuir de modo decidido a la promoción de la prevención, tanto de accidentes de trabajo como de enfermedades profesionales.

- Contribuir notablemente a la mejora de las condiciones de trabajo en las obras.

- Elevar la conciencia preventiva de Direcciones Facultativas de obra, Estamentos administrativos, Estructuras políticas estatales, autonómicas y locales, Grupos Profesionales, Trabajadores y sus Representantes.

Para ello:

- Debe partirse del análisis de las causas técnicas y organizativas de los riesgos más comunes y graves.

- Deben tomarse en consideración las iniciativas de los técnicos y profesionales en prevención del sector.

- Deben desarrollarse acciones de información, asesoramiento y formación en materia preventiva.
- Deben proponerse a los Poderes Públicos medidas concretas estandarizadas a aplicar según experiencia contrastada.

El organismo a poner en marcha debe quedar definido por las características:

- Profesional.

- Preventivo.

- Paritario.

- Estatal.

- Autonómico.

La composición y presencia de los miembros en los órganos de dirección estatal y autonómica deben ser de manera paritaria de las organizaciones más representativas, tanto de la Patronal como de las Centrales Sindicales.

Las funciones concretas de esta estructura estatal deben de ir en la línea siguiente:

1.-Determinar, conforme a la política general de prevención:

- Las orientaciones del organismo.

- Los programas anuales y plurianuales.

- Los calendarios de actividades.

2.-Promocionar, coordinar, controlar la actuación de los Comités Autonómicos y Provinciales.

3.-Elevar propuestas legislativas de Normas y Reglamentos.

4.-Proponer a los Poderes Públicos medidas y reglamentos estandarizados a aplicar según experiencia contrastada.

5.-Fijar condiciones de admisión de profesionales y prevencionistas, así como nombrar al Responsable Estatal y Responsables Autonómicos y Provinciales.

La financiación puede ser mediante tres vías:

a) Tasa de cotización.

b) Subvención Estatal.

c) Fondos sociales de las Mutuas de accidentes de trabajo. 


\section{CONCLUSIONES}

Estamos en un momento importante:

- Hemos diseñado un marco de entendimiento, entre Patronal y Centrales Sindicales, a través del Convenio General y, en concreto, de la Fundación Laboral que se ha de poner en marcha.

- Existe una prevención creciente entre profesionales y prevencionistas-técnicos de aplicar extensa y específicamente el RD 555/86 y RD 84/90.
- Estamos a las puertas de tener una nueva Ley de Prevención de Riesgos Profesionales que marcará las actuaciones prevencionistas.

- Estamos enmarcados en el contexto europeo y, definitivamente, hemos de ponernos al día en Normativa, aplicación de la misma, participación y coordinación de todos los agentes implicados en el proceso constructivo en favor de la prevención.

\section{publicaciones del ICCET / CSIC}

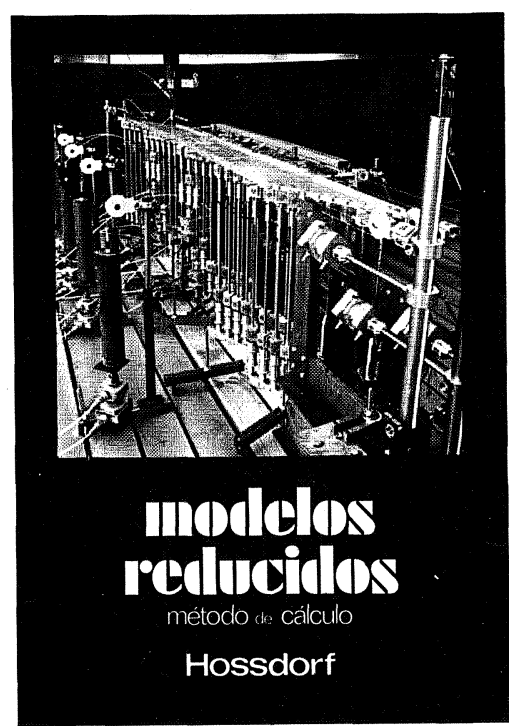

Modelos reducidos. Método de cálculo

H. Hossdorf, Ingeniero Civil

La técnica de los ensayos en modelos reducidos de estructuras sufre hoy dia una decisiva metamorfosis. Hasta hace poco era un medio más bien de artesania, que no siempre era tomado en serio por los académicos teorizantes Dara comprender el comportamiento resistente de las estucturas complejas $y$ que se acudió las más de las veces, como a un ultimo remedio debido a sus indisculby $y$ gracias a su cias. Sin embargo, en poco lispo y gracias a su conexión con los ordenadores dintificam se ha transformado en un instur un que no puede quedar a un lado en la practica

Un volumen encuadernado en cartoné plastificado Un volumen encuadernado $24 \mathrm{~cm}$, compuesto de 250 páginas, 158 figuras $y$ fotografias.

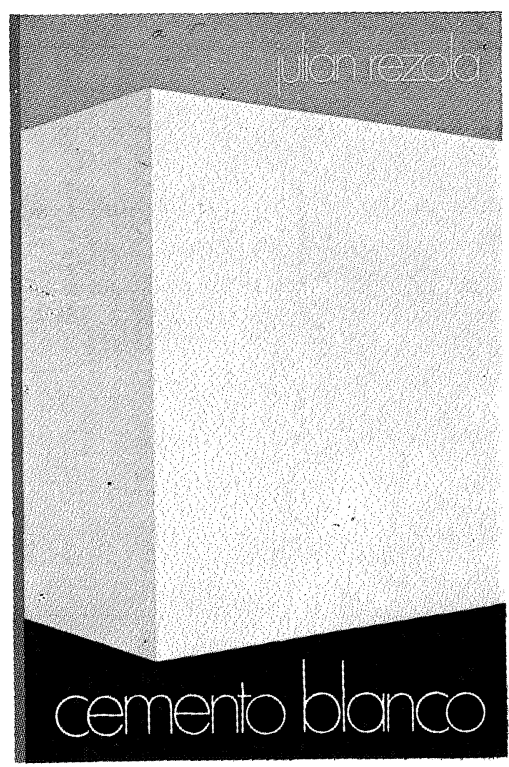

Cemento blanco

Julián Rezola

Ingeniero Químico Dipl. I. Q. S.

Sabido es que existe una extensa y documentada bibliografia sobre el cemento gris: en cambio, no puede decirse lo mismo acerca del cemento portland puede decirse lo mismo ace existentes se refieren tan solo a algunas peculiaridades que le distinguen de aquél.

El autor nos ofrece sus profundos conocimientos y su larga experiencia tanto en laboratorio como en fabricación.

La parte descriptiva del libro se complementa con gráficos, diagramas y fotografías de gran utilidad destinados a conseguir la aplicación apropiada de este aglomerante.

Un volumen encuadernado en cartoné policerado, de $17,4 \times 24,3 \mathrm{~cm}$, compuesto de 395 páginas, numerosas figuras, tablas y ábacos.

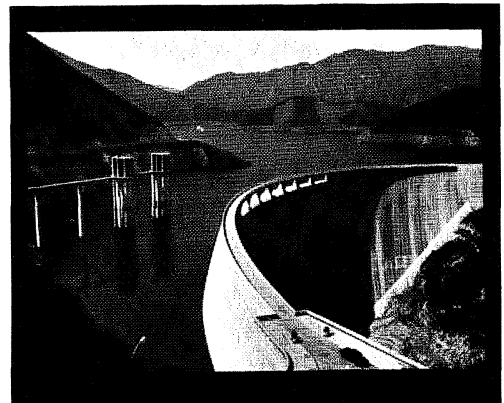

la presa bóveda de Susqueda

su proyecto construcción y comportamiento

A.Rebollo

La presa bóveda de Susqueda

A. Rebollo,

Dr. Ingeniero de Caminos

El esfuerzo del constructor de presas se sitúa, por su pretensión de perennidad, a contracorriente de las tendencias de la civilización actual, caracterizada por to fungible. Pueden evocarse las 10.000 grandes. presas en funcionamiento o en construcción que están envejeciendo y reclaman los cuidados gerontológicos para mantener $y$ perfeccionar su perennida perenidad, En la medida en que todas nuevas riesgos acolos o pequenas, son portaforas de aumentan con el envecimiento, la gerontos, que las presas es todo un emplazo. La accion adelantada las presuro Rebollo a seguir para todos los que aman su propia obra con la devoción paternal que d ha puesto en Susqueda.

Un volumen encuadernado en cartoné plastificado con lomo de tela, de $18 \times 24,5 \mathrm{~cm}$, conpuesto de 408 páginas, 330 figuras $y$ fotografias $y 39$ tablas. 